\title{
Influence of microflora on texture and contents of amino acids, organic acids, and volatiles in semi-hard cheese made with DL-starter and propionibacteria
}

\author{
U. Rehn, ${ }^{\star}$ F. K. Vogensen, ${ }^{\star}$ S.-E. Persson,† K. Hallin Saedén,‡ B. F. Nilsson,§ and Y. Ardö*1 \\ *Department of Food Science, Faculty of Life Sciences, University of Copenhagen, Rolighedsvej 30, DK-1958 Frederiksberg C, Denmark \\ †Milko, Norra Kilaforsvägen 81, SE-821 30 Bollnäs, Sweden \\ ‡Norrmejerier, Mejerivägen 2, SE-906 22 Umeå, Sweden \\ §Skånemejerier, Näsbyholmsvägen 1, SE-291 22 Kristianstad, Sweden
}

\begin{abstract}
The microflora of semi-hard cheese made with DLstarter and propionic acid bacteria $(\mathrm{PAB})$ is quite complex, and we investigated the influence of its variation on texture and contents of organic acids, free amino acids, and volatile compounds. Variation in the microflora within the normal range for the cheese variety Grevé was obtained by using a PAB culture in combination with different DL-starters and making the cheeses at 2 dairy plants with different time and temperature profiles during ripening. Propionic acid bacteria dominated the microflora during ripening after a warm room period at levels of $\log 8$ to $\log 9$ $\mathrm{cfu} / \mathrm{g}$, which was about $1 \log$ unit higher than the total number of starter bacteria and about 2 log units higher than the number of nonstarter lactic acid bacteria. Eye formation was observed during the warm room period and further ripening (at 8 to $10^{\circ} \mathrm{C}$ ). The amounts of acetate, propionate, total content of free amino acids, 2-propanol, and ethyl propionate in the ripened cheeses were related to the number of PAB. A decrease in the relative content of Asp and Lys and increase of Phe over the ripening time were different from what is observed in semi-hard cheese without PAB. The occurrence of cracks was higher in cheeses with more hydrolyzed $\alpha_{S^{-}}$and $\beta$-casein, higher content of free amino acids, lower strain at fracture (shorter texture), and a greater number of PAB.
\end{abstract}

Key words: cheese texture, propionic acid bacteria, microflora, DL-starter

\section{INTRODUCTION}

Propionic acid bacteria (PAB) are added to semihard cheese varieties such as Jarlsberg and Maasdamer, as well as to hard cheese varieties such as Emmental. Grevé is a semi-hard Swedish cheese with PAB, which

Received February 8, 2010.

Accepted November 2, 2010

${ }^{1}$ Corresponding author: ya@life.ku.dk contribute to characteristic large round eyes and a sweet and nutty flavor (Ardö, 1993, 2004). Grevé is made from pasteurized cow milk using mesophilic DLstarter (where DL = diacetylactis-Leuconostoc), which results in a rather complex microflora comprising several strains of 4 types of starter lactic acid bacteria $(\mathbf{L A B}), \mathrm{PAB}$, and undefined nonstarter lactic acid bacteria (NSLAB).

Lactate produced by the starter bacteria during cheese making and early ripening is the primary source of energy for PAB in cheese, and it is converted mainly into propionate, acetate, and $\mathrm{CO}_{2}$. Three different pathways for the utilization of lactate by PAB have been described, and all 3 pathways have been observed simultaneously in Emmental cheese (Wyder et al., 2001; Fröhlich-Wyder and Bachmann, 2004). The growth of $\mathrm{PAB}$ is promoted by increasing the ripening temperature during a warm room period, when the enhanced production of $\mathrm{CO}_{2}$ contributes to eye formation (Fröhlich-Wyder and Bachmann, 2004). In semi-hard cheese with DL-starter and PAB, several strains of Lactococcus lactis ssp. lactis biovar. diacetylactis (Lc. diacetylactis) and Leuconostoc from the starter produce gas from citrate before the warm room period and may thereby initiate eye formation. The formation of eyes is a crucial step for texture development during ripening, and undesired texture defects such as cracks may occur, and are especially pronounced in cheese with gasproducing bacteria. The occurrence of texture defects in cheese is thought to result from a combination of several factors such as gas production at low temperatures by certain PAB (Park et al., 1967; Hettinga, et al., 1974), stimulation of PAB by high proteolytic activity of LAB (Baer and Ryba, 1999; Thierry et al., 1999; White et al., 2003), short texture of cheese (because of its physiochemical composition; Grappin et al., 1993), and microbial decarboxylation of Glu resulting in gas production (Zoon and Allersma, 1996). Apparently, a too high activity of $\mathrm{PAB}$ during ripening may be an important factor (Wyder et al., 2001: Fröhlich-Wyder et al., 2002; White et al., 2003). 
The fracture properties of cheese (i.e., properties that reflect the strength of the bonds in the cheese matrix) are important for proper eye formation in Gouda-type cheese (Luyten and van Vliet, 1996). Fracture properties, including the shortness of the cheese, are associated with the chemical composition such as moisture, $\mathrm{pH}$, calcium, salt, and fat (Grappin et al., 1993) as well as grade of proteolysis (Luyten and van Vliet, 1996).

The scientific literature on ripening of semi-hard cheese with mesophilic DL-starter and PAB is limited compared with that on cheese made with thermophilic starter and PAB. A comparison between Jarlsberg and a similar semi-hard cheese but without PAB, showed a characteristic high content of organic acids involved in the lactate fermentation by PAB, but also a higher content of other components, such as orotic, pyruvic, formic, and pyroglutamic acids (Pripp et al., 1999b). In the same study, semi-hard cheese with and without PAB differed in contents of amino acids and small peptides. Several studies have identified intracellular peptidase activities of $\mathrm{PAB}$ that could be active in cheese and that release amino acids (Sahlström et al., 1989; Perez Chaia et al., 1990; El-Soda et al., 1992; Tobiassen et al., 1997). On the other hand, the general proteolytic activity of PAB is generally lower than that of lactococci and lactobacilli (Pripp et al., 1999a).

The volatile compounds 2-methylbutanol and 2-methylbutanal (derived from Ile) were found at higher levels in Maasdamer than in semi-hard cheese without PAB, in which the contents of 3-methylbutanol and 3-methylbutanal (derived from Leu) were higher (Engels et al., 1997). In Emmental cheese, the production of esters and organic acids by PAB is considered to contribute to typical flavor (Thierry et al., 2004a,b, 2005). For semihard cheese in general, the aroma contribution from the starter involves production of diacetyl from citrate and conversion of free amino acids into aroma compounds (Parente and Cogan, 2004; Ardö, 2006).

The aim of this study was to investigate the influence of variations in microbial composition occurring during industrial cheese production and ripening on texture and composition of free amino acids, organic acids, and volatile compounds in Grevé, a semi-hard cheese with mesophilic DL-starter and PAB.

\section{MATERIALS AND METHODS}

Grevé cheeses were obtained from 8 industrially made vats; 2 of each were produced using 4 cheese manufacture schemes (referred to as experimental groups G1 to G4). The cheeses were made on full production scale at 2 dairy plants located $440 \mathrm{~km}$ apart in northern Sweden. Groups 1 and 2 were made at one dairy plant and G3 and G4 at another from pasteurized bovine milk using calf rennet $(75 / 25$ of chymosin and bovine pepsin, 180 international milk clotting units; Kemikalia, Skurup, Sweden). The cheese-making procedures used a cooking temperature up to approximately $40^{\circ} \mathrm{C}$ at both plants. Three commercially available mesophilic DLstarters with a mixture of undefined strains (obtained from Chr. Hansen A/S, Hørsholm, Denmark) were used as bulk starters and were precultured at the dairies before addition to the cheese vats. Cheeses of groups G1 and G3 were made with the same starter, which was precultured differently for G1 and G3, and G2 and G4 were made with 2 other starters. The PAB culture (Propionibacterium freudenreichii ssp. shermanii SMR 1137) used for all experimental groups was obtained from Kemikalia (Lund, Sweden; now produced by Sacco, Cadorago, Italy).

Ripening contained 3 main periods; a drying period, a warm room period, and a final ripening period. The 2 dairies used different time and temperature profiles during ripening (P1 and P2; Table 1). The surfaces of the cheeses were waxed and no surface flora was allowed to grow. Cheese samples were taken for analysis after brining, before and after the warm room period, and after $4 \mathrm{mo}$ of ripening. Analysis of organic acids, $\mathrm{pH}$, and moisture content was performed at all sampling points, whereas analyses of LAB, PAB, casein, and amino acids were performed on samples before and after the warm room period and on the ripened cheeses. Fracture properties were analyzed on samples taken before the warm room period and on the ripened cheeses. Volatile compounds, $\mathrm{Ca}$, and $\mathrm{NaCl}$ were analyzed in the ripened cheeses, and FDM was analyzed before brining.

Sensory assessment of texture was performed on cheeses ripened for 4 mo. Furthermore, the cutting of the cheeses ( 475 cheeses corresponding to 24 to $88 \%$ of the total number of cheeses from each vat, respectively) before packaging and selling was documented with a web camera (Axis, Lund, Sweden), and the images were manually evaluated to assess the occurrence of cracks.

\section{Gross Composition}

Analysis of FDM was performed on the fresh cheese (before brining) at the 2 dairies using FoodScan (Foss, Hillerød, Denmark). The Ca content was analyzed by inductively coupled plasma mass spectroscopy (according to Dansk Standard, 2002), and $\mathrm{NaCl}$ content was analyzed in the ripened cheeses according to IDF (2006); analysis of $\mathrm{Ca}$ and $\mathrm{NaCl}$ was performed at $\mathrm{Eu}-$ rofins Steins Laboratory (Holstebro, Denmark).

Moisture content of cheese was measured by drying of grated cheese samples according to IDF (2004). The $\mathrm{pH}$ was measured with a $\mathrm{pH}$ electrode into a tightly packed grated cheese sample with a suitable amount 
Table 1. Chemical composition of the cheeses shown as mean values of results from the 2 vats of each experimental group (G1 to G4) and the standard deviations of differences between the duplicated experiments (SD-diff)

\begin{tabular}{|c|c|c|c|c|c|c|c|c|c|}
\hline \multirow[b]{2}{*}{ Group } & \multirow[b]{2}{*}{ Profile $^{1}$} & \multirow{2}{*}{$\begin{array}{c}\text { FDM } \\
(\% \text { wt/wt }) \\
\begin{array}{c}\text { Before } \\
\text { brining }\end{array}\end{array}$} & \multicolumn{4}{|c|}{ Moisture (\%) } & \multirow[t]{2}{*}{$\mathrm{pH}$} & \multirow{2}{*}{$\begin{array}{c}\mathrm{NaCl} \\
(\% \mathrm{wt} / \mathrm{wt})\end{array}$} & \multirow[t]{2}{*}{$\begin{array}{c}\mathrm{Ca} \\
(\% \mathrm{wt} / \mathrm{wt}\end{array}$} \\
\hline & & & $\begin{array}{c}\text { After } \\
\text { brining }\end{array}$ & $\begin{array}{l}\text { Before } \\
\text { warm } \\
\text { room }\end{array}$ & $\begin{array}{l}\text { After } \\
\text { warm } \\
\text { room }\end{array}$ & Ripened & & & \\
\hline G1 & $\mathrm{P} 1$ & 48.2 & 45.3 & 44.5 & 43.1 & 42.4 & 5.56 & 1.36 & 0.89 \\
\hline G2 & $\mathrm{P} 1$ & 46.8 & 44.8 & 44.5 & 43.7 & 41.6 & 5.57 & 1.32 & 0.91 \\
\hline SD-diff & & 0.4 & 0.2 & 0.4 & 0.1 & 0.1 & 0.01 & 0.04 & 0.01 \\
\hline
\end{tabular}

${ }^{1} \mathrm{P} 1=$ dry storage $5 \mathrm{~d} / 10^{\circ} \mathrm{C}$; warm room $14 \mathrm{~d} /$ temperature $(\mathrm{T})+4^{\circ} \mathrm{C}$; ripening storage $100 \mathrm{~d} / 10^{\circ} \mathrm{C}$; $\mathrm{P} 2=$ dry storage $17 \mathrm{~d} / 10^{\circ} \mathrm{C}$; warm room 14 $\mathrm{d} / \mathrm{T}^{\circ} \mathrm{C}$; ripening storage $81 \mathrm{~d} / 8^{\circ} \mathrm{C} . \mathrm{T}+4^{\circ} \mathrm{C}<20^{\circ} \mathrm{C}$.

of deionized water added. Moisture content and $\mathrm{pH}$ measurements were performed at our laboratory at the University of Copenhagen.

\section{Enumeration of $L A B$}

Aseptic sampling was made in duplicate from the interior of one cheese from each vat at each sampling occasion. Total number of LAB was enumerated on De Man, Rogosa and Sharpe (MRS) agar (Merck, Darmstadt, Germany) with $\mathrm{pH}$ adjusted to 6.5 using $1 \mathrm{M}$ $\mathrm{NaOH}$, and enumeration of NSLAB was performed on MRS agar with $\mathrm{pH}$ adjusted to 5.4 using $1 \mathrm{M} \mathrm{HCl}$. Plates were incubated anaerobically (AnaeroGen, Oxoid, Basingstoke, UK) at $30^{\circ} \mathrm{C}(\mathrm{MRS}$ at $\mathrm{pH} 6.5)$ and $37^{\circ} \mathrm{C}$ (MRS at $\mathrm{pH} 5.4$ ) for $72 \mathrm{~h}$.

\section{Enumeration of $\mathrm{Cit}^{+}$Bacteria}

Cheese samples taken before and after the warm room period were analyzed for citrate-positive $\left(\mathbf{C i t}^{+}\right)$ starter bacteria using calcium citrate agar (KCA) modified from the method described by Nickels and Leesment (1964) (1 L; tryptone $20.0 \mathrm{~g}$, yeast extract $10.0 \mathrm{~g}$, gelatin $2.0 \mathrm{~g}$, lactose $10.0 \mathrm{~g}, \mathrm{NaCl} 4.0 \mathrm{~g}$, trisodium citrate $\cdot 2 \mathrm{H}_{2} \mathrm{O} \quad 8.0$ g, calcium lactate $5 \mathrm{H}_{2} \mathrm{O} \quad 2.0$ $\mathrm{g}$, agar-agar $15.0 \mathrm{~g}, \mathrm{pH}$ adjusted to 6.7 , sterilized at $121^{\circ} \mathrm{C}$ for $15 \mathrm{~min}$ ). Immediately before the agar was poured into the plate, calcium citrate suspension (300 $\mathrm{mL}$ : carboxymethyl cellulose powder $4.5 \mathrm{~g}$, tri-calcium citrate $4 \mathrm{H}_{2} \mathrm{O} 30 \mathrm{~g}$, sterilized at $121^{\circ} \mathrm{C}$ for $15 \mathrm{~min}$ ) was added together with whey filtrate $[1 \mathrm{~L}$ of acidified milk, centrifuged at $1,500 \times g$ after $1 \mathrm{~h}$ at $50^{\circ} \mathrm{C}$, filtered through an S\&S 595 filter (Schleicher \& Schuell BioScience, Dassel, Germany), boiled for 15 min, centrifuged at $1,500 \times g$, filtered through an S\&S 595 filter, and sterilized at $115^{\circ} \mathrm{C}$ for $10 \mathrm{~min}$ ] giving a final mixture of $85 \%$ agar, $10 \%$ whey filtrate, and 5\% calcium citrate suspension. Plates were incubated anaerobically at $25^{\circ} \mathrm{C}$ for $4 \mathrm{~d}$. Up to 24 colonies with clear zones $\left(\mathrm{Cit}^{+}\right.$ bacteria) were isolated from agar plates and stored in MRS broth ( $\mathrm{pH}$ adjusted to 6.5 with $1 M \mathrm{NaOH}$ ) at $-80^{\circ} \mathrm{C}$ until analysis to differentiate between $L c$. diacetylactis and Leuconostoc.

\section{Differentiation of $\mathrm{Cit}^{+}$Isolates}

Isolates from KCA taken from the cheeses before and after the warm room period (as described in previous section) were spotted and grown on KCA with the addition of 5-bromo-4-chloro 3-indolyl- $\beta$-D-galaktopyranosid (X-gal) in dimethyl sulfoxide $(0.04 \mathrm{mg} / \mathrm{mL}$ agar) to differentiate Leuconostoc (blue colonies) from $L c$. diacetylactis (white colonies; media modified from Nickels and Leesment, 1964 according to Vogensen et al., 1987). Plates were incubated anaerobically at $25^{\circ} \mathrm{C}$ until colonies were visible. Plates were then incubated aerobically for $1 \mathrm{~d}$ to allow blue color from the conversion of X-gal to develop.

\section{Enumeration of PAB}

Cheese samples were spread on sodium lactate agar (1 L: sodium lactate $15 \mathrm{~g}$, tryptone $10 \mathrm{~g}$, yeast extract $10 \mathrm{~g}, \mathrm{~K}_{2} \mathrm{HPO}_{4} 0.25 \mathrm{~g}, \mathrm{MgSO}_{4} \cdot 7 \mathrm{H}_{2} \mathrm{O} 0.20 \mathrm{~g}, \mathrm{MnSO}_{4} \cdot \mathrm{H}_{2} \mathrm{O}$ $0.005 \mathrm{~g}$, agar-agar $15 \mathrm{~g}, \mathrm{pH}$ adjusted to 7.0 before sterilization at $121^{\circ} \mathrm{C}$ for $15 \mathrm{~min}$; Østlie et al., 1995). Plates were incubated anaerobically at $30^{\circ} \mathrm{C}$ for $7 \mathrm{~d}$, and light brown colonies were counted as PAB.

\section{Analysis of Organic Acids}

Two grams of grated cheese was added to $5 \mathrm{~mL}$ of deionized water, $0.7 \mathrm{~mL}$ of $0.5 M_{2} \mathrm{SO}_{4}$, and $20.0 \mathrm{~mL}$ of acetonitrile. The samples were shaken for $30 \mathrm{~min}$ and then centrifuged at $2,300 \times g$ for $15 \mathrm{~min}$. The clear supernatant was filtered (0.2- $\mu \mathrm{m}$ Millex filter, Millipore, Bedford, MA) before analysis with HPLC, which was 


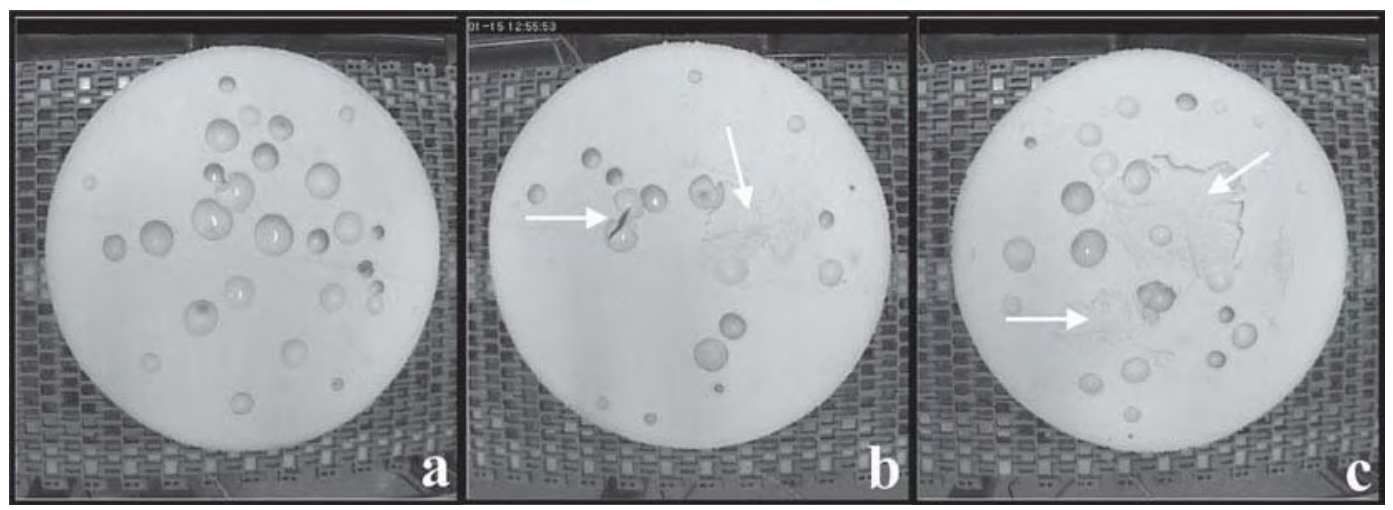

Figure 1. Examples of grading in the image assessment of crack frequency: (a) no cracks, (b) cracks, and (c) severe cracks. Cracks are indicated with arrows. Note that the cheeses were cut opposite to the direction of pressing and through the splits.

performed at University of Life Sciences (Ås, Norway), as described by Skeie et al. (2008).

\section{Cheese Grading}

Sensory assessment of texture was performed according to national Swedish regulations for Grevé. The texture of 1 randomly picked 4-mo-ripened cheese from each experimental vat was assessed by 8 assessors regarding eyes and cracks. Grades were given on a scale ranging from 1 to 9 as follows: $9=$ according to product description with extra high quality; $8=$ according to product description; $7-6=$ minor defects; $5-4=$ obvious defects; $3-2=$ serious defects; $1=$ very serious defects. Grades must be higher than 3 for the product to be approved as Grevé.

The horizontally cut area of the each cheese (cut through the cheese cylinder) was documented with a web camera (Axis) during cutting of the cheeses for packaging and selling. An image evaluation of the texture of the horizontally cut cheese was performed manually by dividing cheeses into 3 categories: no cracks, cracks, and severe cracks (Figure 1). For groups G1 and G2, each vat contained 144 cheeses, and for groups G3 and G4, each vat contained 120 cheeses. Cheeses from groups G1 and G2 were cut for sale and photographed after $10 \mathrm{mo}$, whereas those from G3 after $12 \mathrm{mo}$, and those from G4 after 14 mo of ripening.

\section{Texture Analysis}

Cheese was sampled from a 3-cm-thick cheese block taken from the central part (horizontally) of a quarter of a cheese with cylindrical shape. As many samples as possible were cut from each block. The number of samples from each vat varied between 8 and 18 because of variations in the occurrence of eyes and cracks, which were avoided. Cheese samples were taken in the press- ing direction with a cheese borer. Cylindrical samples (height $20 \mathrm{~mm}$ and diameter $15 \mathrm{~mm}$ ) were placed in closed Petri dishes and allowed to temper at $16^{\circ} \mathrm{C}$ for 2 $\mathrm{h}$ before analysis.

Uniaxial compression was performed with an Instron 5564 Universal Testing Machine (Instron Ltd., High Wycombe, UK) equipped with lubricated steel plates. The velocity of compression was constant at $50 \mathrm{~mm} /$ min. Based on the force and displacement data and with the assumption that the sample maintained its volume and cylindrical shape through the compression, stress $(\sigma)$ and Hencky strain $\left(\varepsilon_{H}\right)$ were calculated. The Hencky strain is defined as follows:

$$
\xi_{x}=\left|\ln \frac{r_{e}}{r_{0}}\right|,
$$

where $H_{0}$ is the initial sample height and $H_{t}$ is the sample height at time $t$ (Steffe, 1996). The stress and Hencky strain at fracture (values at the fracture point) were defined as the first local maximum at the stress and Hencky strain curve.

\section{Analysis of Casein}

Casein components were analyzed on a citrate suspension of cheese as described by Ardö and Polychroniadou (1999). Samples were diluted (volume ratio 1:1) in urea sample buffer and analyzed by using capillary electrophoresis (CE) as described by Jensen et al. (2009). Integrated areas of $\alpha_{\mathrm{S} 1}$-casein, $\beta$-casein, and $\alpha_{\mathrm{S} 1}$-I-casein were divided by migration time to obtain normalized values for comparison between the cheeses.

\section{Analysis of Free Amino Acids}

Analysis of the amino acid composition was performed by reverse-phase HPLC using precolumn derivatization 
with o-phtaldialdehyde (Agilent, Birkerød, Denmark) and fluoroenylmethyl chloroformate (Agilent) as described by Bütikofer and Ardö (1999). Standard curves were used to calculate the amount of amino acids in millimoles per kilogram of cheese. Results are also presented as the relative content calculated as percentage of total amount of amino acids (mol \%).

\section{Analysis of Volatile Compounds}

Volatile compounds were purged from a mixture of cheese and water $(80 \mathrm{~g}$ of cheese, $100 \mathrm{~mL}$ of tap water, and $1 \mathrm{~mL}$ of 4-methyl-1-pentanol as internal standard) with an $\mathrm{N}_{2}$ flow of $200 \mathrm{~mL} / \mathrm{min}$ during $1 \mathrm{~h}$ at $30^{\circ} \mathrm{C}$ onto a Tenax trap and then desorbed, cryofocused, and transferred to a GC-MS equipment. Gas chromatography-mass spectrometry was performed as described by Juric et al. (2003). Integrated areas of the peaks were divided by the area of an internal standard (4-methyl1-pentanol) and are presented as relative response.

\section{Data Analysis}

Results of chemical analyses are presented as mean values for each experimental group (G1 to G4), which represent 2 vats of cheeses, and the standard deviation of the differences between the repeated experiments. Statistical analysis (one-way ANOVA) was performed on results from analysis of volatile compounds to compare results of experimental groups with different $\mathrm{PAB}$ growth in the warm room (G1 and G2 vs. G3 and G4) using the software R, version 2.8.1 (2008; The R Foundation for Statistical Computing, Vienna, Austria). For the multivariate data analysis of the relative content of free amino acids, LatentiX 2.0 (Latent5, Copenhagen, Denmark) was used. All data were weighted with the inverse value of the standard deviation and presented as bi-plots using principal components (PC)1 and 2 .

\section{RESULTS}

\section{Gross Composition of Cheese}

The fat content in DM was 46.8 to $48.2 \%$ (wt/wt) with a standard deviation between repeated experiments (SD-diff) of $0.2 \%$ (Table 1). The $\mathrm{pH}$ developed similarly in all cheeses during ripening (results not shown), and the $\mathrm{pH}$ in the 4-mo-ripened cheeses was around 5.6. The calcium content was similar in all experimental groups $(0.9 \%$, wt/wt; Table 1$)$. The moisture content of the cheeses decreased by 2 to 3 percentage units from immediately after brining and until 4 mo of ripening, at which time it was 40.3 to $42.4 \%$ moisture. The salt con-

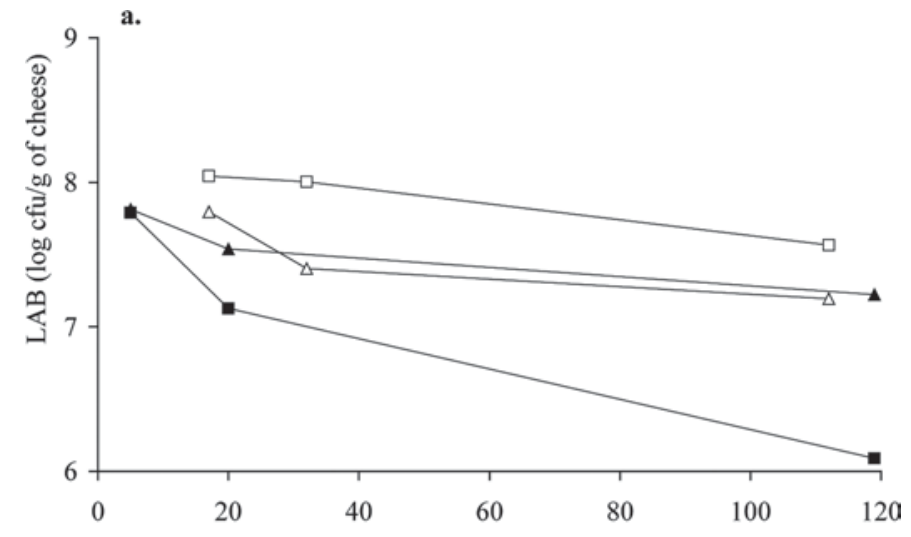

b.

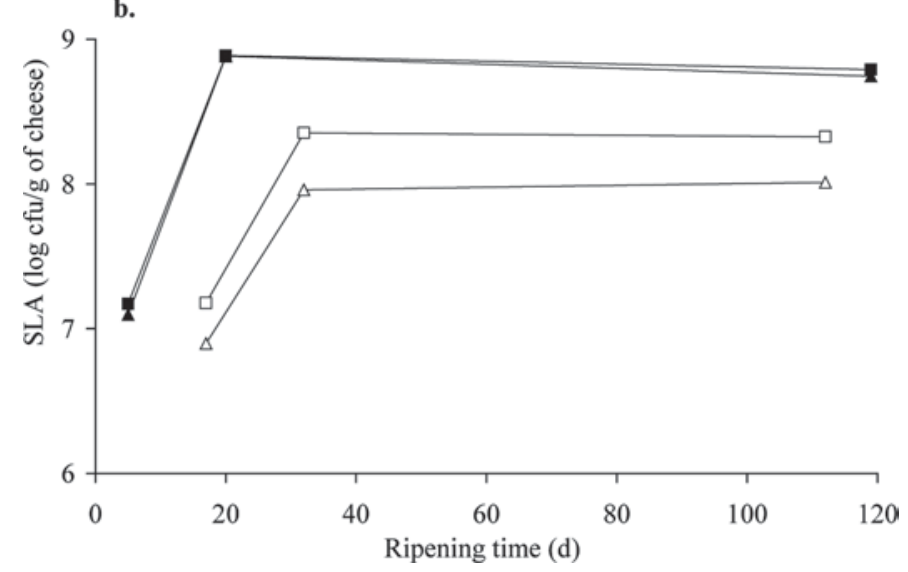

Figure 2. Enumeration of (a) lactic acid bacteria (LAB, on De $\mathrm{Man}$, Rogosa, and Sharpe agar, $\mathrm{pH} 6.5 / 30^{\circ} \mathrm{C}$ ) and (b) propionic acid bacteria (on sodium lactate agar, SLA) in cheese from experimental groups G1 $(\mathbf{\square})$, G2 $(\mathbf{\Delta})$, G3 $(\square)$, and G4 $(\Delta)$. Values represent the mean of analysis of cheeses from 2 vats in each experimental group. The standard deviation of the difference between the mean of the 2 vats, including all sampling points, was 0.07 and 0.09 for the enumeration of LAB and propionic acid bacteria, respectively.

tents in cheeses of groups G1 and G2 were somewhat higher ( $\sim 0.2$ percentage units) than in G3 and G4.

\section{Microbial Composition}

Four patterns of bacterial development in the experimental groups G1 to G4 were obtained (Figure 2, Tables 2 and 3 ). The amount of cultivable LAB began to decrease in the cheeses during the warm room period. Cheeses in group G1 had a much lower number of $\mathrm{LAB}$ in the ripened cheeses compared with the other cheeses (Figure 2a).

The number of PAB before the warm room period was similar in cheeses from groups G1, G2, and G3 ( $\log 7 \mathrm{cfu} / \mathrm{g}$ of cheese), whereas that in group G4 was slightly lower. During the warm room period, the amount of PAB increased approximately 2 log units in 
Table 2. Number of lactic acid bacteria in cheese (log cfu/g of cheese) before and after the warm room period growing on calcium citrate agar (KCA) and an estimate of the numbers (log cfu/g of cheese) of Lactococcus diacetylactis (white colonies with zone) and Leuconostoc (blue colonies with zone)

\begin{tabular}{|c|c|c|c|c|c|c|}
\hline $\begin{array}{l}\text { Time of sampling } \\
\text { and group }\end{array}$ & Vat & $\begin{array}{c}\text { Total } \\
\text { colonies } \\
\text { on KCA }\end{array}$ & $\begin{array}{c}\text { Colonies } \\
\text { on KCA } \\
\text { without zone }\end{array}$ & $\begin{array}{c}\text { Colonies } \\
\text { with zones } \\
\text { on KCA } \\
\left.\text { (citrate }^{+}\right)\end{array}$ & $\begin{array}{c}\text { White } \\
\text { colonies } \\
\text { with zones } \\
\text { on } \mathrm{KCA}^{1}\end{array}$ & $\begin{array}{c}\text { Blue colonies } \\
\text { with zones } \\
\text { on } \mathrm{KCA}^{1}\end{array}$ \\
\hline \multirow[t]{2}{*}{ G1 } & 1 & 8.0 & 7.6 & 7.8 & 7.4 & 7.5 \\
\hline & 2 & 8.0 & 7.7 & 7.6 & 7.1 & 7.4 \\
\hline G2 & 1 & 7.8 & 7.6 & 7.4 & 7.1 & 7.1 \\
\hline \multirow[t]{2}{*}{ G4 } & 1 & 7.8 & 7.8 & 6.9 & 6.8 & 5.9 \\
\hline & 2 & 8.1 & 8.0 & 7.3 & 7.2 & 6.4 \\
\hline \multicolumn{7}{|l|}{ After warm room } \\
\hline \multirow[t]{2}{*}{ G1 } & 1 & 7.1 & 6.6 & 6.9 & $\mathrm{ND}^{2}$ & 6.9 \\
\hline & 2 & 7.2 & 6.3 & 7.2 & 6.1 & 7.1 \\
\hline G2 & 1 & 7.7 & 6.5 & 7.7 & 6.8 & 7.6 \\
\hline
\end{tabular}

${ }^{1}$ Estimated from several isolates (8 to 24 ) of colonies with zones on KCA.

${ }^{2} \mathrm{ND}=$ not detected.

groups G1 and G2, but only by about $1 \log$ unit in G3 and G4, reflecting an effect of the temperature in the warm room, which was $4^{\circ} \mathrm{C}$ lower for G3 and G4. During the ripening period (after the warm room period), the number of $\mathrm{PAB}$ did not change considerably in any of the cheeses, and the numbers were considerably higher in G1 and G2 compared with G3 and G4. The microflora of all the ripened cheeses was dominated by PAB compared with LAB.

Variations were observed between the experimental groups in the estimated content of $\mathrm{Cit}^{+}$bacteria, likely Lc. diacetylactis and Leuconostoc (Table 2). Before the warm room period, the number of $\mathrm{Cit}^{+}$bacteria in G1, G2, and G3 was between $\log 7.4$ and $8.1 \mathrm{cfu} / \mathrm{g}$, whereas G4 had a somewhat lower content, ranging from log 6.9 to $7.3 \mathrm{cfu} / \mathrm{g}$. Equal numbers of Lc. diacetylactis and Leuconostoc were observed before the warm room period, with the exception of G4 cheeses, which contained a higher number of Lc. diacetylactis than Leuconostoc. During the warm room period, the proportion of $\mathrm{Cit}^{+}$ LAB increased in all cheeses, whereas the total number of LAB decreased. Lactococcus diacetylactis continued to dominate the $\mathrm{Cit}^{+}$bacteria in G4 after the warm room period, whereas Leuconostoc dominated the $\mathrm{Cit}^{+}$ bacteria in the other 3 groups.

The number of colony-forming units on MRS ( $\mathrm{pH}$ 5.4) incubated at $37^{\circ} \mathrm{C}$, as an estimate of the NSLAB, varied between $\log <2$ and $\log 6.4 \mathrm{cfu} / \mathrm{g}$ in the ripened cheeses (Table 3). The numbers tended to decrease during ripening in cheeses from groups G1 and G2, whereas they remained stable in G3. The levels for G4 varied during ripening and were less than $\log 2$ and 3 cfu/g for G4-1 (vat 1 of group 4) before and after the warm room period, respectively. Many of the colonies on the MRS agar at pH 5.4 were small (e.g., pinpoint colonies). Isolates from this medium were identified, by using 16S rRNA sequencing, as mainly Lactobacillus casei but also Leuconostoc sp., Lc. lactis, Enterococcus sp., and Streptococcus sp. (Rehn, 2010) that apparently were able to grow under the conditions chosen for selection of NSLAB.

\section{Organic Acids}

As expected for a cheese with $\mathrm{PAB}$, a decrease in lactate content occurred during the ripening period in

Table 3. Nonstarter lactic acid bacteria (NSLAB) on De Man, Rogosa, and Sharpe (MRS) agar with $\mathrm{pH} 5.4$ and incubated in $37^{\circ} \mathrm{C}$ before warm room (BW), after warm room $(\mathrm{AW})$, and in the ripened cheeses

\begin{tabular}{lcccc}
\hline & & \multicolumn{3}{c}{$\begin{array}{c}\text { NSLAB on MRS pH } 5.4 \\
\text { (cfu/g of cheese) }\end{array}$} \\
\cline { 3 - 5 } Group & Vat & BW & AW & Ripened \\
\hline G1 & 1 & 6.6 & 6.3 & 4.0 \\
G2 & 2 & 6.3 & 6.5 & 3.5 \\
& 1 & 6.0 & 5.6 & 4.7 \\
G3 & 2 & 5.8 & 5.7 & 4.8 \\
& 1 & 6.0 & 6.5 & 6.3 \\
G4 & 2 & 5.8 & 6.3 & 6.4 \\
& 1 & $<2$ & $<3$ & 2.5 \\
& 2 & 3.6 & 5.4 & 3.3 \\
\hline
\end{tabular}


the warm room simultaneously with increases of the contents of propionate, acetate, and succinate (Figure $3)$. After the warm room period, no further lactate was used in cheeses from groups G1 and G2 and no more propionate and acetate was produced; however, more than $65 \%$ of the lactate was already used during the warm room period (Figure 3a). The amount of succinate increased slightly in these cheeses during ripening. In cheeses from groups G3 and G4, only about $20 \%$ of the lactate was used during the warm room period and another $40 \%$ was used after the warm room period in parallel with increases in propionate, acetate, and succinate contents (Figure 3b), but with no further growth of PAB.

The amount of citrate decreased in all cheeses between brining and the warm room period, indicating activity of $\mathrm{Cit}^{+}$starter bacteria (results not shown). Higher amounts of citrate remained after brining in cheeses from groups G2 and G4, indicating lower cit-
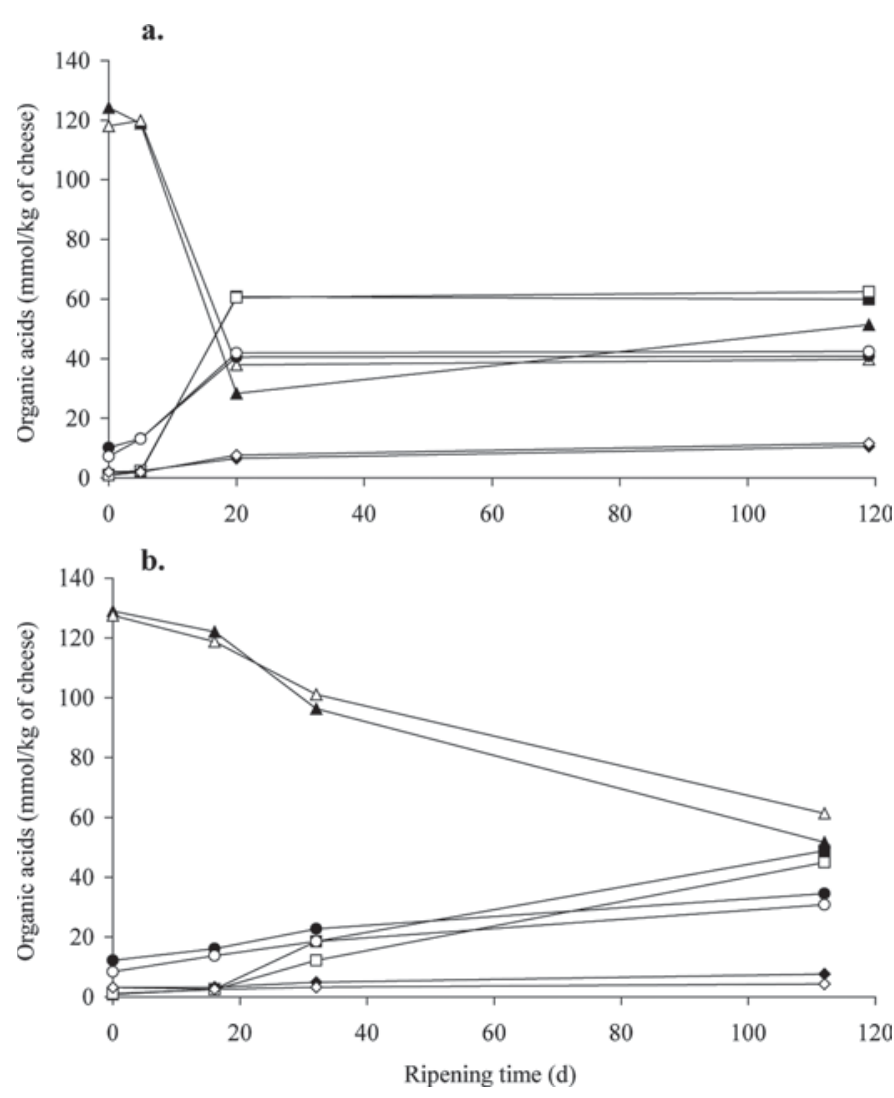

Figure 3. Organic acids $(\mathrm{mmol} / \mathrm{kg}$ of cheese) lactate $(\mathbf{\Lambda} / \Delta)$, propionate $(\square / \square)$, acetate $(\bullet / O)$, and succinate $(\bullet / \diamond)$ in cheese from experimental groups G1 and G2 (a; closed and open symbols, respectively) and groups G3 and G4 (b; closed and open symbols, respectively). Results are presented as an average of analysis of cheeses from the 2 vats in each experimental group, and the standard deviation differences between repeated experiments within each group were 7.9 (lactate), 5.7 (propionate), 2.5 (acetate), and 0.6 (succinate). rate utilization in these cheeses during cheese making and early ripening than in groups G1 and G3. Most of the citrate present in the cheeses after brining (0.78 to $1.84 \mathrm{mmol} / \mathrm{kg}$ ) was, however, used up before the warm room period, after which time the level was $\leq 0.2$ $\mathrm{mmol} / \mathrm{kg}$ of cheese.

\section{Eye Formation, Texture, and Image Assessment}

Eye formation in cheeses from groups G1 and G2 took place mainly during the warm room period, whereas for G3 and G4 the eyes were mainly formed after the warm room period (Figure 4). Larger sizes of the eyes in the 4-mo-ripened cheeses were observed in cheeses from groups G1 and G2 compared with that in G3 and G4.

In the sensory assessment of texture of the 4-moripened cheeses, samples from group G1 received lower scores than those from G2, G3, and G4 (Table 4). Cheeses from groups G3 and G4 were noted to have small eyes or too few eyes, whereas the predominant remarks for cheeses from G1 and G2 were presence of cracks. The randomly picked cheeses from the 2 vats of each experimental group varied considerably in sensory score, which demonstrated a large variation in texture of this type of cheese.

The manual image assessment of the web camera photographs was performed to assess the variation of cracks within a vat. Unfortunately, vat G1-2 was not documented. The occurrence of cracks (including severe cracks) in cheeses from the vats of groups G1 and G2 was between 48 and $72 \%$ of the photographed cheeses, whereas for G3 and G4 the frequency was between 1 and $39 \%$ (Table 4). Thus, the occurrence of cracks was generally higher in cheeses from the groups G1 and G2, whereas the frequency of severe cracks was higher in vat G3-1 compared with all other vats.

\section{Fracture Properties}

Rheological measurements showed that stress at fracture increased and strain at fracture decreased in cheeses of all experimental groups from before the warm room period until ripening for 4 mo (Figure 5). Furthermore, the cheese vats clustered according to dairy plant, and thus time and temperature profile (Table 1, Figure 5), at both time points, and as the cheeses ripened, the differences between the experimental groups increased. Before the warm room period, cheeses from G1 and G2 had lower strain at fracture and lower stress at fracture compared with those from G3 and G4. After 4 mo of ripening, cheeses from groups G1 and G2 were still lower in strain at fracture compared with cheeses in G3 and G4, whereas the difference in stress at fracture was less. 


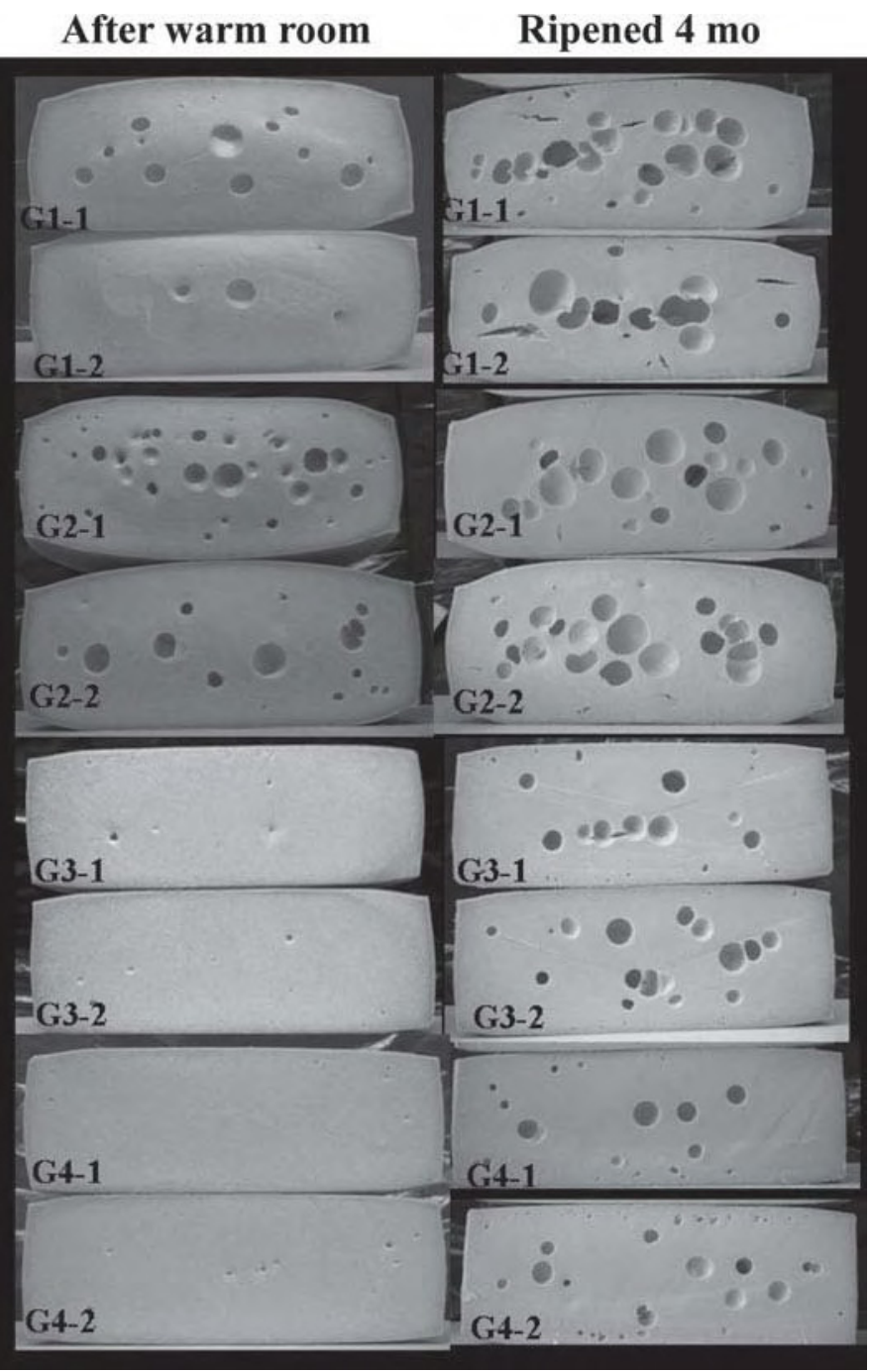

Figure 4. Documentation of eye and crack formation for cheeses in all experimental groups after the warm room period and when ripened for 4 mo. Cheeses are labeled Ga-b, where Ga is the group number and $\mathrm{b}$ is the vat number.

\section{Casein Components}

The breakdown of the casein analyzed using CE showed the proteolytic activities of chymosin on $\alpha_{\mathrm{S1}^{-}}$ casein and plasmin on $\beta$-casein, and the pattern did not vary between the experimental groups of cheeses (results not shown). Integration of the $\mathrm{CE}$ peaks on the electropherogram confirmed that the formation and further breakdown of $\alpha_{\mathrm{S} 1}$-I-casein $\left[\alpha_{\mathrm{S} 1}-\mathrm{CN}\right.$ (f29-199)], typically formed by chymosin activity during ripening, followed a similar pattern in all the experimental groups (Table 5 ). Both $\alpha_{\mathrm{S} 1}$-casein $8 \mathrm{P}$ (with 8 phosphate groups) and $\beta$-casein were hydrolyzed faster in groups G1 and G2 than in G3 and G4 during the warm room period (Table 5).

\section{Free Amino Acids}

Total content of amino acids varied largely between the 4 experimental groups of cheese during ripening (Table 5); the highest content was observed for experimental group G2 and the lowest for G4 throughout ripening. The quantitatively dominating amino acids in the ripened cheeses were Glu, Gln, Val, Leu, Lys, and Pro (results not shown).

Changes in the composition of amino acids during ripening were evaluated by multivariate data analysis (Figure 6). Ripening time could be seen along PC1 (increasing from left to right) with a relatively high amount of Orn in the young cheeses and a series of several amino acids in the ripened cheeses. During the warm room period the experimental groups were mainly separated along $\mathrm{PC} 2$; the relative content of Lys, Ser, and Pro decreased, whereas Glu, Leu, and Phe increased. However, after the warm room period, the relative content of Glu and Leu decreased (except for G4, in which the relative content of Leu continued to increase after the warm room period). The content of Asp varied between 0 and $0.06 \mathrm{mmol} / \mathrm{kg}$ ( 0 to $0.07 \mathrm{~mol}$ $\%$ ) in the cheeses after the warm room period (results not shown), and Asp could not be quantified in the ripened cheeses.

Contents of His and $\gamma$-aminobutyric acid (GABA) were below detection limits before and after the warm room period, but could be quantified in the ripened cheeses from all experimental groups (except GABA in the ripened cheeses of G4). Tryptophan was only slightly over the detection limit in ripened cheese from group G1.

\section{Volatile Compounds}

The analysis of the volatile compounds identified a range of different alcohols, aldehydes, ketones, ethyl esters, and sulfuric compounds (Table 6). The lowest amounts were generally found in cheeses of G4, with exceptions for sulfur compounds that were highest in G3 and G4 and some secondary alcohols. The secondary alcohol 2-propanol, however, was considerably higher in groups G1 and G2. Interestingly, cheeses of G4 had 4 to 7 times the amount of 2-methylpropanol (a breakdown product of Val) than did cheeses of the other groups. Except for 2/3-methylbutanal and, to some extent, benzaldehyde, which were higher in G1 and G2 than in G3 and G4, no large differences were found among the aldehydes. The ethyl esters were present in much higher amounts in cheeses of groups G1 and G2, and levels of ethyl propionate and ethyl octanate were especially pronounced. Because of the faster PAB growth during the warm room period in cheeses 
1106

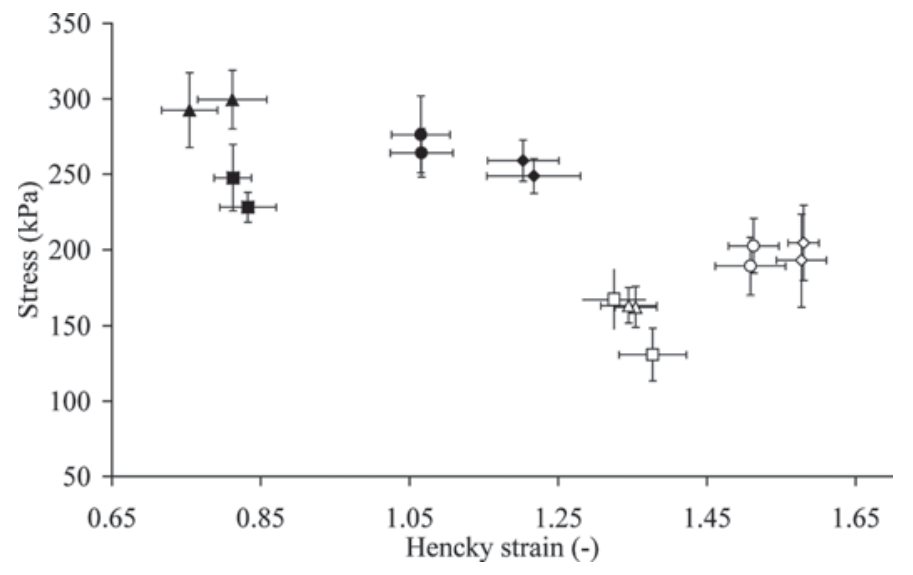

Figure 5. Results from uniaxial compression of the cheeses presented as stress and Hencky strain at fracture, generally considered to represent firmness and shortness, respectively, before warm room (open symbols) and for the 4-mo-ripened cheeses (closed symbols). Values refer to average and standard error of 8 to 18 analyses of each

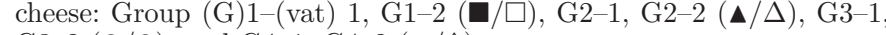
G3-2 $(\bullet / \bigcirc)$, and G4-1, G4-2 $(\bullet / \diamond)$.

of G1 and G2 compared with G3 and G4, a calculation of significant differences between the combined groups G1-G2 and G3-G4, respectively, was made to explore the effect of PAB. The contents of $2 / 3$-methylbutanal and 2/3-methylbutanol were significantly higher $(P<$ 0.01) in G1-G2 compared with in G3-G4 (Table 6). The 2 peaks for 2-methylbutanal and 3-methylbutanal were not completely separated; however, the peak for 2-methylbutanal was clearly higher than the other, indicating a general higher content of 2-methylbuta- nal than 3-methylbutanal (Table 6). The contents of 2-propanol, 3-methyl-3-butenol, benzaldehyde, and 4-methyl-2-pentanone were significantly higher $(P<$ 0.01) in groups G1-G2 compared with G3-G4, as was the content of ethyl esters (Table 6). The contents of several alcohols and sulfur compounds were, on the other hand, significantly higher in the combined group G3-G4.

\section{DISCUSSION}

Large variation was obtained in the microflora of the cheeses from the 4 experimental groups, in which all cheeses were assessed as typical Grevé. The content of $\mathrm{LAB}$ decreased during ripening from $\log 8$ in all cheeses before the warm room period, but to different extents, which can be explained by variations in the composition of the bulk starters used and by different influences from manufacturing conditions.

It was concluded that the higher temperature in the warm room for groups G1 and G2 had a considerable effect on the growth of PAB. A lower content of $\mathrm{Cit}^{+}$ starter bacteria before the warm room period was observed in cheeses of group G4, which had fewer PAB after the warm room period than cheeses of group G3 that were ripened at the same temperature. This indication of a relation between the composition of starter bacteria and PAB in the cheese needs further investigation. Lactococcus diacetylactis dominated the LAB flora before and after the warm room period in cheeses from group G4, whereas Leuconostoc dominated the LAB flora of the other cheeses after the warm room period.

Table 4. Results from sensory texture assessment (scores refer to an average of 8 assessors) with standard deviations (SD) after 4 mo of ripening, and results from assessment of images of cheeses after cutting

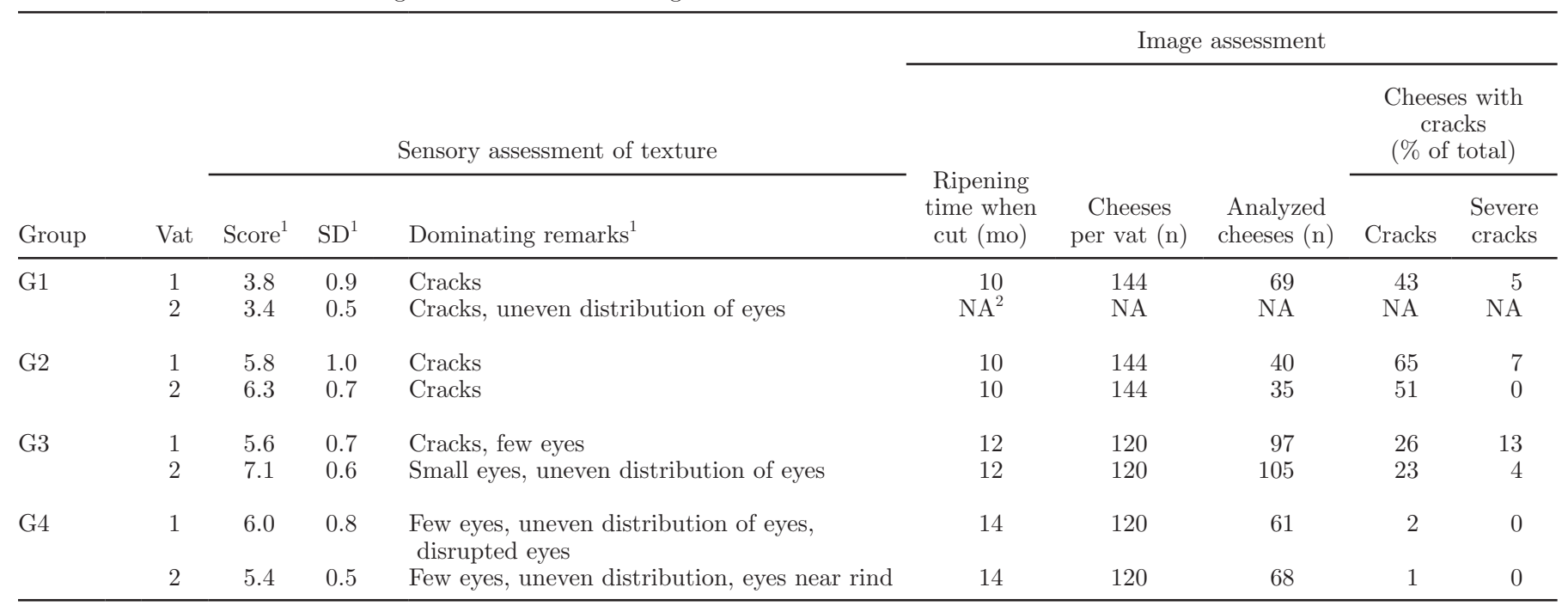

\footnotetext{
${ }^{1}$ Scores and standard deviations (SD) refer to an average of 8 assessors, and the dominating remarks were given by more than 2 assessors.

${ }^{2} \mathrm{NA}=$ not analyzed.
} 
The ratio between Lc. diacetylactis and Leuconostoc is likely influenced by differences in the bulk starter composition.

Counts of LAB on MRS at pH 5.4 were lower than those on MRS at $\mathrm{pH} 6.5$ throughout ripening, which indicates a dominance of starter bacteria over NSLAB. However, the difference between counts on the 2 media could, to some extent, be explained by the fact that not all NSLAB that grew on MRS with $\mathrm{pH} 6.5$ at $30^{\circ} \mathrm{C}$ were able to grow on MRS with pH 5.4 at $37^{\circ} \mathrm{C}$. We conclude that the NSLAB did not grow to dominating microbial numbers within the $4 \mathrm{mo}$ of ripening; however, they may have had some influence on the long-time-ripened cheeses from, for example, group G3, in which counts were above $\log 6 \mathrm{cfu} / \mathrm{g}$ after $4 \mathrm{mo}$.

The levels of lactate, propionate, and acetate showed a clear relation to the dairy plant, most likely because of the different temperatures in the warm room, which would be expected because of the variations in growth of $\mathrm{PAB}$. The number of $\mathrm{PAB}$ increased only during the warm room period, whereas eyes were formed as a result of gas production during both the warm room period (mainly in groups G1 and G2) and the ripening period (mainly in groups G3 and G4), which showed that the strain of $\mathrm{PAB}$ used was able to produce gas from lactate at temperatures as low as $8^{\circ} \mathrm{C}$.

The results from analysis of large deformations of the cheeses reflected an increase in firmness (increase in stress at fracture) and shortness (decrease in Hencky strain at fracture) of the cheeses during 4 mo of ripening. The cheeses from groups G1 and G2 were significantly shorter (lower strain at fracture) compared with G3 and G4 throughout ripening. All cheeses showed an increase in stress at fracture during ripening, and significant differences were observed between the experimental groups. Differences in strain at fracture before the warm room period may be explained by different ages of the cheeses: $5 \mathrm{~d}$ between brining and warm room (G1 and G2) gives the curd granules less time to fuse

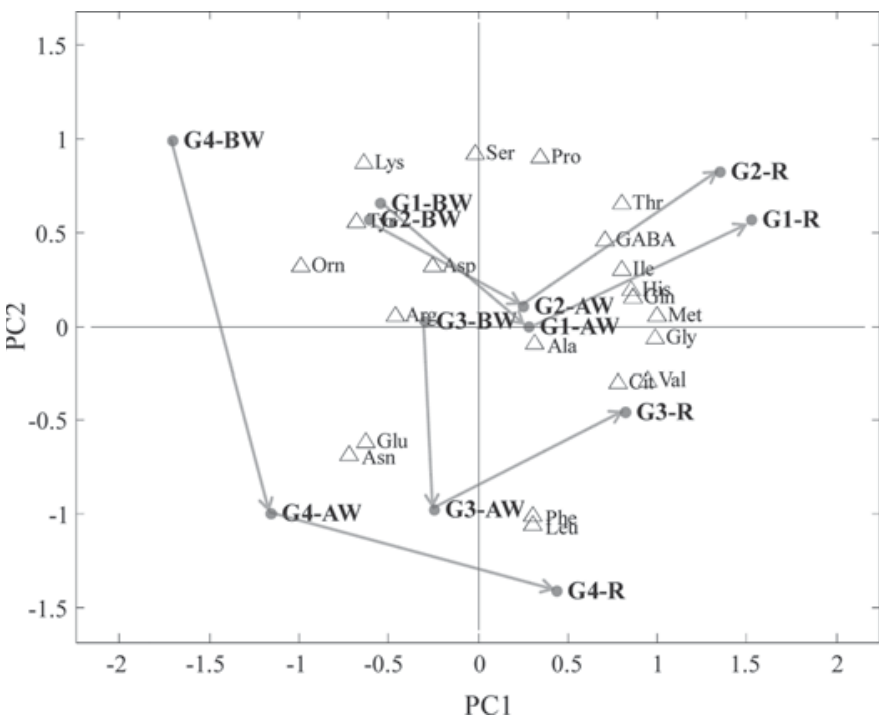

Figure 6. Principal components (PC) analysis bi-plot of the relative content of amino acids (mol \%) in the cheeses during ripening ( $\mathrm{BW}=$ before warm room, $\mathrm{AW}=$ after warm room, $\mathrm{R}=$ ripened $)$. Explained variance: PC1 47\% and PC2 20\%. The principal components analysis was calculated from mean values for each experimental group with 2 repetitions. The SD for most amino acids was $<0.2 \mathrm{~mol}$ $\%$, or the CV (SD as \% of mean values) was $<10 \%$.

compared with $17 \mathrm{~d}$ (G3 and G4), and a rearrangement of minerals (e.g., Ca) takes place during early maturation, which has been shown to have an effect on the texture of cheese (Lucey et al., 2003).

Cheeses from groups G1 and G2 with the highest number of PAB were noted to have more cracks, both after 4 mo and about $1 \mathrm{yr}$ of ripening, compared with cheeses from groups G3 and G4. A possible explanation of the higher frequency of cracks may involve lower strain at fracture as well as higher numbers of $\mathrm{PAB}$ that may produce gas when the texture is shorter, causing cheeses to be more prone to cracking. The decrease in strain at fracture over ripening time is typical for

Table 5. Amounts of $\alpha_{\mathrm{S}_{1}} \mathrm{CN} 8 \mathrm{P}$ (with 8 phosphate groups), $\alpha_{\mathrm{S} 1}-\mathrm{I}-\mathrm{CN} 8 \mathrm{P}$, and $\beta$-CN presented as an average of the normalized area of the casein peaks of electropherograms of cheeses and total amounts of amino acids before warm room (BW), after the warm room (AW), and in the ripened cheeses ${ }^{1}$

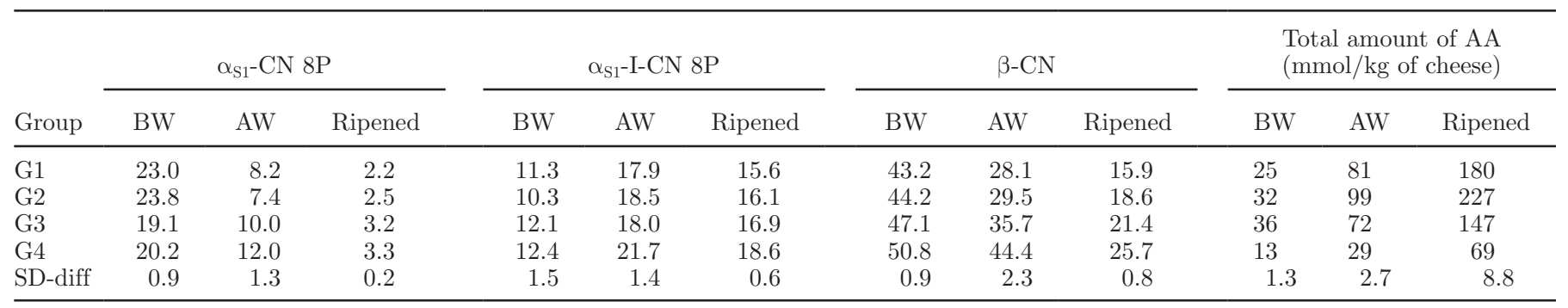

${ }^{1}$ Results are mean values of cheeses from the 2 vats in each experimental group (G1 to G4). Standard deviations are of differences between duplicated experiments within each experimental group (SD-diff). 
Table 6. Volatile compounds in the 4-mo-ripened cheeses $^{1}$

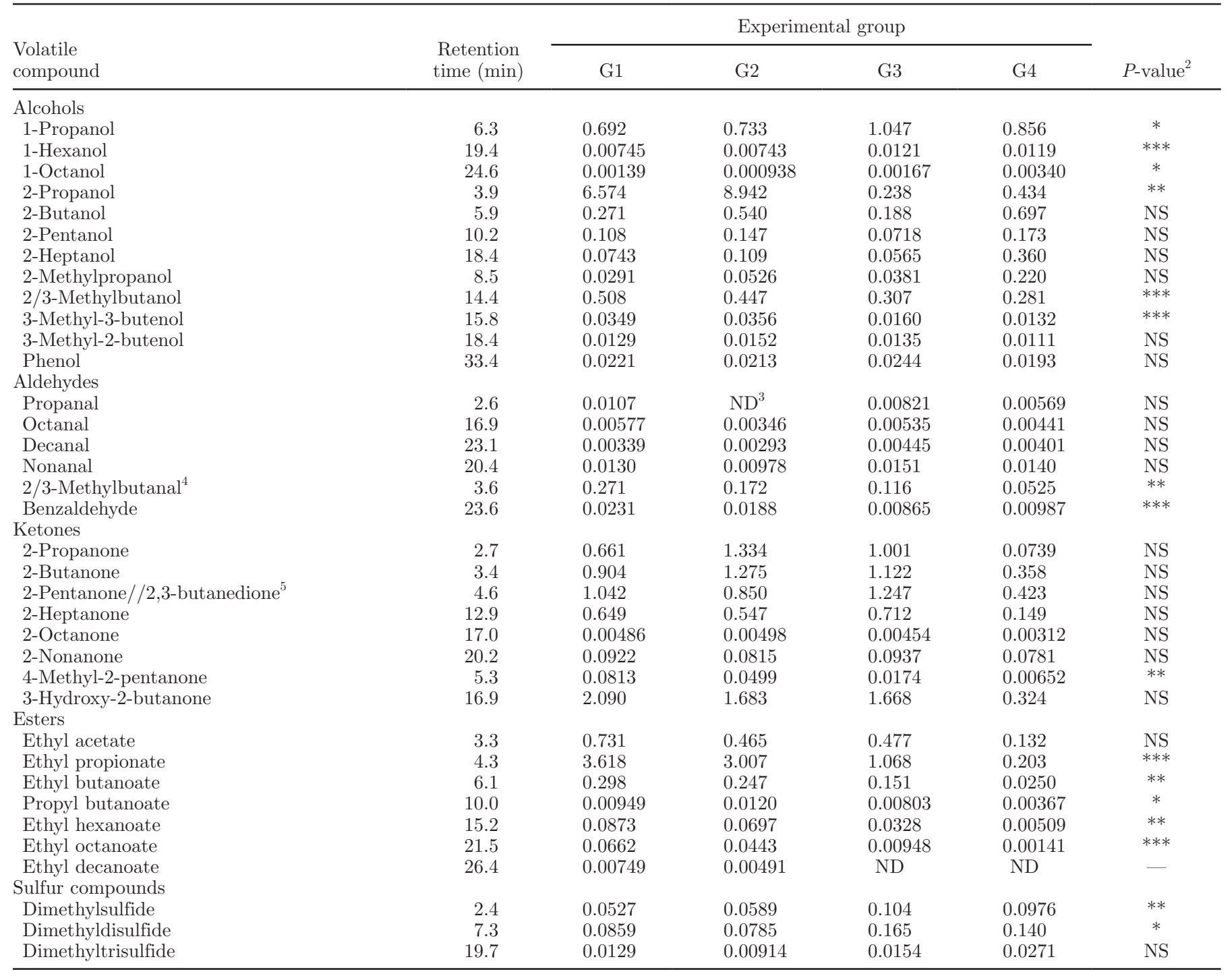

${ }^{1}$ Results are presented as relative response to internal standard and shown as mean values of triplicate analysis of cheeses from each of the 2 vats in each experimental group. Coefficient of variation (CV, difference between the 2 vats in percentage of the mean) was between 5 and $43 \%$ with an average of $20 \%$, and the largest CV was found for the sulfur compounds. One-way ANOVA was performed between experimental groups with different increase in content of propionic acid bacteria during the warm room period (2 log units for G1 and G2 versus 1 log unit for G3 and G4).

${ }^{2}$ One-way ANOVA of joint experimental groups G1-G2 and G3-G4.

${ }^{3} \mathrm{ND}=$ not detected.

${ }^{4} 3$-Methylbutanal appeared as a shoulder on 2-methylbutanal.

${ }^{5}$ 2-Pentanone and 2,3-butanedione (diacetyl) co-eluted in the same peak and could not be separated by mass spectra.

$* P<0.05 ; * * P<0.01 ; * * * P<0.001$.

semi-hard cheeses (Luyten and van Vliet, 1996) as well as for Emmental cheese (Bachmann et al., 1999).

The assessment of images of the long-time-ripened cheeses showed that the frequency of severe cracks was highest in cheeses from vat G3-1 compared with all other vats, and a randomly picked cheese from this vat was noted to have more cracks after 4 mo of ripening. Vat G3-2, which was produced immediately after vat
G3-1, had a lower frequency of severe cracks, illustrating the complexity of the occurrence of these structural defects. Furthermore, the origin of severe cracks may be different from that of moderate cracks, such as lumps in the vat and uneven pressing procedure. Higher degradation of $\alpha_{\mathrm{S}^{-}}$and $\beta$-caseins and a higher content of free amino acids were observed for cheeses in groups G1 and G2. Deeper proteolysis gives the cheese a shorter 
texture (also shown by a lower Hencky strain), which cannot withstand the pressure of $\mathrm{CO}_{2}$ and may therefore have a greater tendency to develop cracks (Grappin et al., 1993). This factor likely contributed to the higher frequency of cracks in cheeses of groups G1 and G2.

The higher total content of amino acids in the ripened cheeses from groups G1 and G2 than from G3 and G4 may be explained by the higher temperature in the warm room $\left(+4^{\circ} \mathrm{C}\right)$, which generally induces greater microbial activity. Furthermore, influence from the microbial composition and lysis of the different lactic acid bacteria could influence amino acid release. The content of small peptides and amino acids has been shown to be higher in semi-hard cheese with PAB (Jarlsberg) compared with similar cheese without PAB (Norvegia; Pripp et al., 1999b).

During ripening of the cheeses, the relative contents of Asp and Lys generally decreased, whereas that of Phe increased, the opposite of what has been observed for semi-hard cheese without PAB (Herrgård; Ardö et al., 2002). The decrease of the content of Asp (mmol/ $\mathrm{kg}$ ) during the warm room period may be explained by PAB activity, in agreement with Crow and Turner (1986). The differences seen in the development of relative contents of Glu and Leu (first increasing and then decreasing) and Ser (first decreasing and then increasing) during the warm room period and the period after the warm room, respectively, indicated the dominance of different microbial activities during these 2 ripening periods. Earlier studies have shown that PAB are able to catabolize Ser and Glu (Antila, 1957; Brendehaug and Langsrud, 1985; Crow, 1987). Thus, the composition of the amino acids during the warm room period was likely affected by $\mathrm{PAB}$; however, the relative decrease in Leu could be a result of LAB activities after the warm room period (Ardö et al., 2002). The changes in amino acid composition during the warm room period may also involve lysis of the starter bacteria, which declined in numbers during this period.

The increase in relative content of GABA and decrease in Glu during ripening after the warm room period in cheeses from G1 and G2 indicated decarboxylation of Glu to GABA, a process that also results in $\mathrm{CO}_{2}$ production. Similar results have also been observed in Emmental (Wyder et al., 2001), and the ability to decarboxylate Glu into GABA has been observed in Propionibacterium freudenreichii (Beck and Schink, 1995). Thus, the higher content of GABA in G1 and G2 is likely due to PAB activity, but an effect from LAB cannot be excluded. Decarboxylation of Glu has been found in Lactobacillus brevis (Ueno et al., 1997) and in a Lc. diacetylactis strain from a mesophilic DL-starter (Nomura et al., 1998).
Several aroma compounds, especially 2 -propanol and ethyl propionate, were extracted in higher amounts from cheeses in groups G1 and G2, where ethyl propionate may be of most importance for characteristic flavor (Thierry et al., 2004b). If the higher content of 2 -propanol is a result of $\beta$-oxidation, it would result from an increased lipolytic activity on butyric acid, but this need further investigation. Branched chain compounds such as 2-methylbutanal (derived from Ile), 3-methylbutanal, and 3-methylbutanol (derived from Leu) are typically present in cheeses with PAB (Thierry et al., 2005). These compounds were found in all cheeses, although 2-methylbutanol and 3-methylbutanol could not be separated by the GC method used. However, 3-methylbutanal and 2-methylbutanal were partly separated and the result indicated a higher content of 2-methylbutanal than 3-methylbutanal. The contents of 2/3-methylbutanal and 2/3-methylbutanol were higher in G1 and G2 than in G3 and G4, which could be explained by higher numbers of PAB. This is in accordance with results of experiments with Maasdamer showing that PAB may have a higher activity against Ile than Leu (Engels et al., 1997).

\section{CONCLUSIONS}

Propionic acid bacteria were present at the highest number of all bacteria groups in the cheese microflora from the warm room period onwards, followed by starter bacteria and then NSLAB. The changes in the relative contents of Asp, Lys, and Phe over ripening time were different compared with that in semi-hard cheese without PAB. The number of $\mathrm{PAB}$ obtained during ripening in the warm room was correlated to the temperature, and the amount of acetate, propionate, free amino acids, 2-propanol, and ethyl propionate in the ripened cheeses were related to the number of PAB. Eye formation was observed during the warm room period and later ripening. The texture became more firm (higher stress at fracture) and shorter (lower strain at fracture) during the 4 mo of ripening. Cheeses with a lower strain at fracture, more hydrolyzed casein, and a higher number of PAB had a higher frequency of cracks observed after 4 mo and after 1 yr of ripening.

\section{ACKNOWLEDGMENTS}

The authors thank Local Agricultural Research for Northern Sweden (Regional Jordbruksforskning för Norra Sverige, RJN, LRF, Bollstabruk, Sweden) for financing the work. We thank Norrmejerier (Umeå, Sweden) and Milko (Bollnäs, Sweden) for supplying cheese samples. Mehdi Darestani Farahani, Anni Nielsen Bager, 
and Mona Østergaard (University of Copenhagen) and Kari Olsen and Olga Shapovalova (University of Life Sciences, Ås, Norway) are acknowledged for excellent technical performance. Camilla Varming (University of Copenhagen, Denmark) and Anders Ola Karlsson (formerly of University of Copenhagen, Denmark) are thanked for fruitful discussions. Håkan Ardö (Centre of Mathematical Science, Lund University, Sweden) is acknowledged for administrating the digital documentation from the web cameras and for fruitful discussions.

\section{REFERENCES}

Antila, M. 1957. Der aminosäureabbau durch Propionsäurebakterien. Finn. J. Dairy Sci. 18:3-6.

Ardö, Y. 1993. Swedish cheese varieties. Pages 254-256 in Cheese: Chemistry, Physics and Microbiology, Vol 2. 2nd ed. P. F. Fox, ed., Chapman \& Hall, London, UK.

Ardö, Y. 2004. Semihard Scandinavian cheese made with mesophilic DL-starter. Pages 277-290 in Handbook of Fermented Food and Beverages. H. Hui, L. Meunier-Goddik, Å. Solveijg Hansen, J. Josephsen, W.-K. Nip, P. S., Stanfield, and F. Toldra, ed. Marcel Dekker Inc., New York, NY.

Ardö, Y. 2006. Flavour formation by amino acid catabolism. Biotechnol. Adv. 24:238-242.

Ardö, Y., and A. Polychroniadou. 1999. Laboratory Manual for Analysis of Cheese. Office for Official Publications of the European Communities, Luxembourg.

Ardö, Y., B. V. Thage, and J. S. Madsen. 2002. Dynamics of free amino acid composition in cheese ripening. Aust. J. Dairy Technol. 57:109-115.

Bachmann, H. P., U. Butikofer, and J. Meyer. 1999. Prediction of flavour and texture development in Swiss-type cheeses. Food Sci. Technol. 32:284-289.

Baer, A., and I. Ryba. 1999. Interactions between propionic acid bacteria and thermophilic lactic acid bacteria. Lait 79:79-92.

Beck, S., and B. Schink. 1995. Acetate oxidation through a modified citric acid cycle in Propionibacterium freudenreichii. Arch. Microbiol. 163:182-187.

Brendehaug, J., and T. Langsrud. 1985. Amino acid metabolism in propionibacteria: Resting cells experiments with four strains. J. Dairy Sci. 68:281-289.

Bütikofer, U., and Y. Ardö. 1999. Quantitative determination of free amino acids in cheese. Bull. Int. Dairy Fed. 337:24-32.

Crow, L. 1987. Properties of alanine dehydrogenase and aspartase from Propionibacterium freudenreichii ssp. shermanii. Appl. Environ. Microbiol. 58:1885-1892.

Crow, V. L., and K. W. Turner. 1986. The effect of succinate production on other fermentation products in Swiss-type cheese. N. Z. J. Dairy Technol. 21:217-227.

Standard, D. 2002. Foodstuffs. Determination of trace elements. Pressure digestion. DS13805:2002-ICP-OES. Charlottenlund, Denmark.

El-Soda, M., N. Ziada, and N. Ezzat. 1992. The intracellular peptidehydrolase system of Propionibacterium. Microbios 72:65-74.

Engels, W. J. M., R. Dekker, C. de Jong, R. Neeter, and S. Visser. 1997. A comparative study of volatile compounds in the water soluble fraction of various types of ripened cheese. Int. Dairy J. 7:255-263.

Fröhlich-Wyder, M. T., and H. P. Bachmann. 2004. Cheeses with propionic acid fermentation. Pages $142-156$ in Cheese: Chemistry, Physics and Microbiology. Vol 2. 3rd ed. P. F. Fox, P. L. H. McSweeney, T. M. Cogan, and T. P. Guinee, ed. Elsevier Academic Press, London, UK.

Fröhlich-Wyder, M. T., H. P. Bachmann, and M. G. Casey. 2002. Interaction between propionibacteria and starter/non-starter lactic acid bacteria in Swiss-type cheeses. Lait 82:1-15.
Grappin, R., D. Lefier, G. Dasen, and S. Pochet. 1993. Characterising ripening of Gruyere de Comté: Influence of time x temperature and salting conditions on eye and slit formation. Int. Dairy J. 3:313-328.

Hettinga, D. H., G. W. Reinbold, and E. R. Vedamuthu. 1974. Split defect of Swiss cheese. I. Effect of strain of Propionibacterium and wrapping material. J. Milk Food Technol. 37:322-328.

International Dairy Federation. 2004. Cheese and processed cheese Determination of the total solids content. IDF Standard 004/ISO 5543. Int. Dairy Fed., Brussels, Belgium.

International Dairy Federation. 2006. Cheese and processed cheese products - Determination of chloride content-Potentiometric titration method. Standard 88/ISO 5943. Int. Dairy Fed., Brussels, Belgium.

Jensen, M. P., F. K. Vogensen, and Y. Ardö. 2009. Variation in caseinolytic properties of six cheese related $L b$. helveticus strains. Int. Dairy J. 19:661-668.

Juric, M., G. Bertelsen, G. Mortensen, and M. A. Petersen. 2003. Light-induced colour and aroma changes in sliced, modified atmosphere packaged semi-hard cheeses. Int. Dairy J. 13:239-249.

Lucey, J. A., M. E. Johnson, and D. S. Horne. 2003. Invited review: Perspectives on the basis of the rheology and texture properties of cheese. J. Dairy Sci. 86:2725-2743.

Luyten, H., and T. van Vliet. 1996. Effect of maturation on large deformation and fracture properties of (semi-)hard cheeses. Neth. Milk Dairy J. 50:295-307.

Nickels, C., and H. Leesment. 1964. Methode zur differenzierung und quantitativen bestimmung von Säureweckerbakterien. Milchwissenschaft 19:374-378.

Nomura, M., H. Kimot, Y. Someya, S. Furukawa, and I. Suzuki. 1998. Production of gamma amino butyric acid by cheese starters during ripening. J. Dairy Sci. 81:1486-1491.

Østlie, H. M., V. Floberghagen, G. W. Reinbold, E. G. Hammond, G. Vegarud, and T. Langsrud. 1995. Autolysis of dairy propionibacteria: Growth studies, peptidase activities, and proline production. J. Dairy Sci. 78:1224-1237.

Parente, E., and T. Cogan. 2004. Starter cultures: General aspects. Pages 123-147 in Cheese: Chemistry, Physics and Microbiology, Vol 2. 3rd ed. P. F. Fox, P. L. H. McSweeney, T. M. Cogan, and T. P. Guinee, ed. Elsevier Academic Press, London, UK.

Park, H. S., G. W. Reinbold, and E. G. Hammond. 1967. Role of Propionibacteria in split defect of Swiss cheese. J. Dairy Sci. 50:820-823.

Perez Chaia, A., A. Pesce de Ruiz Holgado, and G. Oliver. 1990. Peptide hydrolases of propionibacteria: Effect of $\mathrm{pH}$ and temperature. J. Food Prot. 53:237-240.

Pripp, A. H., A. Kieronczyk, L. Stepaniak, and T. Sørhaug. 1999b. Comparison of biochemical characteristics of three Norwegian cheese varieties using multivariate statistical analysis. Milchwissenschaft 54:558-562.

Pripp, A. H., L. Stepaniak, and T. Sørhaug. 1999a. Proteolysis in cheese curd as affected by subcellular fractions from Lactococcus, Lactobacillus and Propionibacterium. J. Food Sci. 64:353-358.

Rehn, U. 2010. Ripening of characteristic cheese varieties with mesophilic DL-starter with focus on microflora and texture of cheese with Propionibacterium. $\mathrm{PhD}$ thesis. University of Copenhagen, Frederiksberg, Denmark.

Sahlström, S., C. Espinosa, T. Langsrud, and T. Sørhaug. 1989. Cell wall, membrane, and intracellular peptidase activities of Propionibacterium shermanii. J. Dairy Sci. 72:342-350.

Skeie, S., A. Kieronczyk, R. M. Naess, and H. Østlie. 2008. Lactobacillus adjuncts in cheese: Their influence on the degradation of citrate and serine during ripening of a washed curd cheese. Int. Dairy J. 18:158-168.

Steffe, J. F. 1996. Rheological Methods in Food Process Engineering. 2nd ed. Freeman Press, East Lansing, MI.

Thierry, A., M. B. Maillard, C. Herve, R. Richoux, and S. Lortal. 2004b. Varied volatile compounds are produced by Propionibacterium freudenreichii in Emmental cheese. Food Chem. 87:439446. 
Thierry, A., M. B. Maillard, R. Richoux, J. R. Kerjean, and S. Lortal. 2005. Propionibacterium freudenreichii strains quantitatively affect production of volatile compounds in Swiss cheese. Lait 85:57-74.

Thierry, A., R. Richoux, and J. R. Kerjean. 2004a. Isovaleric acid is mainly produced by Propionibacterium freudenreichii in Swiss cheese. Int. Dairy J. 14:801-807.

Thierry, A., D. Salvat-Brunaud, and J. L. Maubois. 1999. Influence of thermophilic lactic acid bacteria strains on propionibacteria growth and lactate consumption in an Emmental juice-like medium. J. Dairy Res. 66:105-113.

Tobiassen, R. O., L. Stepaniak, and T. Sørhaug. 1997. Screening for differences in the proteolytic systems of Lactococcus, Lactobacillus and Propionibacterium. Z. Lebensm. Unters. Forsch. A 204:273278.

Ueno, Y., K. Hayakawa, S. Takahashi, and K. Oda. 1997. Purification and characterisation of glutamate decarboxylase from Lactobacillus brevis IFO 12005. Biosci. Biotechnol. Biochem. 61:1168-1171.
Vogensen, F. K., T. Karst, J. J. Larsen, B. Kringelum, D. Ellekjaer, and E. W. Nielsen. 1987. Improved direct differentiation between Leuconostoc cremoris, Streptococcus lactis ssp. diacetylactis, and Streptococcus cremoris/Streptococcus lactis on agar. Milchwissenschaft 42:646-648.

White, S. R., J. R. Broadbent, C. J. Oberg, and D. J. McMahon. 2003. Effect of Lactobacillus helveticus and Propionibacterium ssp shermanii combinations on propensity for split defect in Swiss cheese. J. Dairy Sci. 86:719-727.

Wyder, M.-T., J. O. Bosset, M. G. Casey, D. Isolini, and H. Sollberger. 2001. Influence of two different propionibacterial cultures on the characteristics of Swiss-type cheese with regard to aspartate metabolism. Milchwissenschaft 56:78-81.

Zoon, P., and D. Allersma. 1996. Eye and crack formation in cheese by carbon dioxide from decarboxylation of glutamic acid. Neth. Milk Dairy J. 50:309-318. 